\title{
La Motxilla Bioclimàtica
}

\author{
Àngel Sedó Camp d'Aprenentatge Juneda (Dept. Ensenyament) \\ Núria Fontova Associació Lo Secanet \\ Jérôme Barrau Universitat de Lleida \\ Manel Ibáñez Universitat de Lleida $\bowtie$
}

Presentem la Motxilla Bioclimàtica, una proposta que té per objectiu educar en ciències, medi ambient $i$ salut partint d'un context quotidià. La Motxilla Bioclimàtica facilita a l'equip de professors $i$ alumnes un conjunt d'eines per avaluar la qualitat ambiental i bioclimàtica de les aules.

Paraules clau: educació ambiental, balanç d'energia, mesura, qualitat ambient interior, bioclimatisme

\section{El per què}

El medi ambient i la salut son les àrees de medi natural més rellevants socialment i significatives per a l'educació primària i secundària.

Però el diàleg entre la educació ambiental, l'educació per la salut i l'educació científica sovint no és planer. Potser sigui per influències històriques $i$ culturals però creiem que també per dificultats metodològiques (Zeyer i Dillon, 2012).

En aquest sentit cal una nova mirada que aporti didàctiques adreçades a la integració d'aquests àmbits des de la perspectiva actual de la complexitat. Presentem en aquest treball la Motxilla Bioclimàtica, una proposta didàctica que ha madurat amb l'objectiu d'educar en ciències, medi ambient i salut partint d'un context quotidià.

El projecte educatiu la Motxilla Bioclimàtica és impulsat i coordinat des del Camp d'Aprenentatge de Juneda.

El professorat té a l'abast propostes d'educació ambiental per auditar el consum energètic del seu centre amb l'objectiu de conscienciar els alumnes sobre la limitació dels recursos fòssils, la seguretat energètica o el canvi climàtic. Però molt sovint l'activitat queda deslligada dels continguts científics que la fan possible i gairebé sempre oblida les interrelacions que hi ha entre la despesa energètica al centre i la salut del seus ocupants. Per altra banda, la relació entre les característiques constructives d'un edifici i la seva salubritat és ben coneguda pels arquitectes. Hi ha escoles d'arquitectura bio- climàtica on es treballa tècnicament la relació entre l'edifici, la despesa energètica i la qualitat ambiental interior assolida. La Motxilla Bioclimàtica també apropa aquests coneixements més tecnològics a les aules de secundària.

La funcionalitat dels continguts científics en qualsevol àmbit de l'educació ambiental sempre es fa ben evident quan assolim un grau d'experimentació important. En el cas que ens ocupa, els treballs sobre estalvi i eficiència energètica es transformen en treball científic sempre que la mesura, el tractament de dades, les hipòtesis, etc, entren en joc. La Motxilla Bioclimàtica es planteja com un treball experimental on fer, pensar i comunicar és la seva raó de ser (Pujol, 2003). L'activitat científica porta a plantejar i comprendre qüestions de l'impacte de la nostra activitat sobre l'ambient i sobre la salut.

El lligam entre la despesa energètica al centre i la salut del seus ocupants és fàcil d'intuir però difícil de quantificar. La despesa energètica de l'edifici és una realitat força abstracta per als alumnes. Calia apropar el balanç d'energia al propi cos i a l'aula per relacionar-los amb les condicions ambientals $i$ la gestió de l'aula i la pròpia salut: un repte. En aquest context la Motxilla Bioclimàtica és original en proposar un treball experimental entre professors i alumnes de l'aula i les seves condicions bioclimàtiques amb l'objectiu, en primer terme, de conèixer la seva qualitat a nivell energètic $i$ ambiental. I en segon terme, l'impacte sobre el medi ambient $\mathrm{i}$ la salut dels alumnes. 


\section{El repte}

En el món occidental actual, el manteniment de les condicions ambientals òptimes a l'interior dels edificis s'assoleix en gran mesura augmentant el consum energètic. Valors rècord en el consum d'energia són noticia gairebé cada nou hivern i estiu. La societat no renuncia a viure en òptimes condicions en els ambients interiors, que permeten gaudir de salut, benestar i confort. Ben al contrari, un mal ambient interior interfereix en el rendiment escolar, causa desconfort i irritació, així como problemes de salut en els escolars i el professorat (Bakó-Biró i al., 2007).

Aquesta qualitat ambiental també s'ha d'assolir en les nostres aules. Però ho podem fer malbaratant energia o bé aprofitant els recursos naturals amb una gestió adequada dels espais i una bona arquitectura bioclimàtica de l'edifici. L'impacte d'una i altra forma sobre el medi ambient és ben diferent.

Aquest plantejament ens porta a investigar la qualitat ambiental i la qualitat bioclimàtica de l'aula. La qualitat ambiental dóna una mesura de les condicions de benestar i salut. La qualitat bioclimàtica orienta sobre la sostenibilitat energètica de com assolim aquestes condicions.

La Motxilla Bioclimàtica planteja una primera etapa d'experimentació i treball científic: Són bones les condicions de treball? Quin efectes tenen sobre el nostre rendiment i la salut? Quin impacte energètic té assolir aquest ambient interior? I ofereix d'una banda les eines conceptuals i procedimentals per orientar la tasca i, d'altra banda, els aparells de mesura per portar-la a terme. Un cop avaluada l'aula, una segona etapa d'acció consisteix en una proposta d'educació ambiental i educació per la salut: Què podem fer per millorar la qualitat ambiental interior? Com podem reduir l'impacte energètic del nostre centre?

\section{Les eines}

Per portar a terme la nostra investigació sobre la qualitat ambiental i bioclimàtica de l'aula, la Motxilla Bioclimàtica facilita a l'equip de professors i alumnes un conjunt d'eines. Unes eines -ofertes a través de la plana web als centres interessats que en fan ús de forma parcial o total- que es poden dividir en 5 grans grups:

1) els índexs de qualitat de l'ambient interior

2) els índex de qualitat bioclimàtica

3) els aparells de mesura

4) la Calculadora Bioclimàtica, i

5) l'espai d'intercanvi

\section{Els índexs de qualitat de l'ambient interior}

La primera condició a complir a l'aula per fer l'activitat és que el nostre cos pugui satisfer el balanç tèrmic. Això vol dir que els mecanismes fisiològics de la termo-regulació siguin capaços de portar l'organisme a un estat d'equilibri tèrmic entre el guany d'energia tèrmica (d'origen ambiental i metabòlic) i la seva eliminació. Però l'equilibri tèrmic en si mateix està lluny de proporcionar sensació de confort. L'organisme pot aconseguir satisfer el balanç tèrmic en un ampli ventall de combinacions de situacions ambientals i taxes d'activitat però només una estreta franja d'elles condueix a situacions que les persones reconeixem com a confortables.

L'ésser humà emet un elevat nombre de substàncies: diòxid de carboni, compostos orgànics volàtils, aerosols que poden contenir microorganismes viables o no, vapor d'aigua, etc. De tots ells el més important des del punt de vista quantitatiu és el diòxid de carboni. Això el fa idoni per al càlcul del cabal de ventilació necessari per assolir un ambient de qualitat respiratòria acceptable. Quan els nivells de diòxid de carboni superen certs valors, moltes persones comencen a experimentar incomoditat, mal de cap, cansament i problemes respiratoris, depenent de la concentració i de la durada de l'exposició. Uns símptomes que s'agreugen en el cas dels infants.

La qualitat de la il.luminació als centres educatius és un factor molt important per determinar la velocitat, precisió i confort necessaris per desenvolupar les tasques visuals. La il.luminació ha de satisfer les necessitats psicològiques i emotives dels alumnes, així como influir positivament en el seu comportament i en la capacitat de concentració en la feina.

\section{Els índexs de qualitat bioclimàtica}

Les condicions de l'aula són dinàmiques: en tot moment tenim fluxos de matèria i energia que modifiquen les condicions ambientals interiors.

Per això, un objectiu de la nostra investigació és determinar aquests fluxos per avaluar la sostenibilitat energètica de l'aula. Tots aquest fluxos es combinen en el balanç d'energia tèrmica de l'aula, una relació ben intuïtiva que ens diu que l'energia tèrmica entra, surt o s'emmagatzema en un edifici. Aquests fluxos depenen principalment del disseny arquitectònic de l'edifici, de l'ailllament tèrmic, la massa tèrmica, les finestres, la ventilació controlada per portes i finestres, la infiltració no controlada i l'ús de l'aula. Això implica que es poden modificar i que la gestió eficient de l'aula és a les nostres mans. 
El balanç d'energia diari plantejat dependrà necessàriament de les condicions meteorològiques dels dies estudiats. Per fer els resultats comparables entre localitats i èpoques de l'any s'introdueixen quatre índexs de qualitat bioclimàtica de l'aula. Aquests índexs integren tant el comportament arquitectònic com la gestió que en fan els usuaris.

\section{Els aparells de mesura}

Els índexs de qualitat ambiental és poden avaluar puntualment i mantenen tot els seu sentit però els índexs de qualitat bioclimàtica es basen en un balanç energètic diari a l'aula. Avaluar-los requereix

\begin{tabular}{|c|c|c|}
\hline \multicolumn{3}{|c|}{ Mesures a l'interior de l'aula } \\
\hline & Magnitud & Sensor \\
\hline \multirow[t]{2}{*}{ Activitat } & Ocupació & \\
\hline & Taxa metabòlica & \\
\hline \multirow[t]{4}{*}{ Ambient } & Temperatura & $\begin{array}{l}\text { Sensor Wöhler } \\
\text { CDL } 210\end{array}$ \\
\hline & Humitat relativa & \\
\hline & Concentració $\mathrm{CO}_{2}$ & \\
\hline & Luminància & Luxòmetre PCE-174 \\
\hline \multirow[t]{3}{*}{ Calefacció } & $\begin{array}{l}\text { Temperatura } \\
\text { entrada }\end{array}$ & $\begin{array}{l}\text { Termòmetre } \\
\text { PCE-T390 }\end{array}$ \\
\hline & $\begin{array}{l}\text { Temperatura } \\
\text { sortida }\end{array}$ & \\
\hline & Cabal & Cabalímetre PCE \\
\hline II·luminació & Potència elèctrica & Comptador Efenergy2 \\
\hline $\begin{array}{l}\text { Tancaments } \\
\text { opacs }\end{array}$ & $\begin{array}{l}\text { Temperatura } \\
\text { superfície }\end{array}$ & $\begin{array}{l}\text { Termòmetre infraroig } \\
\text { PCE-888 }\end{array}$ \\
\hline \multirow[t]{2}{*}{ Finestres } & Irradiació & Piranòmetre SPM1 \\
\hline & $\begin{array}{l}\text { Superfície } \\
\text { captació }\end{array}$ & $\begin{array}{l}\text { Distanciòmetre } \\
\text { PCE-LDM50 }\end{array}$ \\
\hline \multicolumn{3}{|c|}{ Mesures a l'exterior de l'aula } \\
\hline \multirow[t]{4}{*}{ Ambient } & Temperatura & $\begin{array}{l}\text { Estació meteorològica } \\
\text { PCE-FWS } 20\end{array}$ \\
\hline & Humitat relativa & \\
\hline & Concentració $\mathrm{CO}_{2}$ & $\begin{array}{l}\text { Sensor Wöhler } \\
\text { CDL } 210\end{array}$ \\
\hline & Irradiació & $\begin{array}{l}\text { Piranòmetre } \\
\text { SPM1 }\end{array}$ \\
\hline
\end{tabular}

dades representatives de tot un dia. Els aparells de mesura a disposició a la Motxilla Bioclimàtica mesuren i emmagatzemen les mesures de forma contínua i segons l'interval que desitgem. Les memòries dels diferents aparells permeten emmagatzemar dades d'uns quants dies i posteriorment descarregar-les a l'ordinador. La taula 1 detalla les 17 variables que mesurarem, acompanyades de l'instrument que emprarem en cada cas.

\section{La Calculadora Bioclimàtica}

La Calculadora Bioclimàtica és l'eina informàtica que facilitat tota la feina de tractament de dades. Tot i que es faciliten els conceptes i relacions per avaluar els índexs proposats a partir de les mesures, es pot emprar aquesta eina si els usuaris volen alleugerir la feina de càlcul, no pas la d'anàlisi dels resultats.

\section{Espai d'intercanvi}

Un cop calculats els diferents índexs bioclimàtics de l'aula és el moment d'avaluar els resultats i passar a l'acció. Com a usuaris de l'espai ens podem plantejar quins canvis es proposen.

Apareixeran, de ben segur, els canvis en l'equipament, que seran més complicats, però es poden analitzar quins elements arquitectònics ajudarien a obtenir millores a l'aula. Un cop haguem decidit, amb tots els companys i companyes, quines són les accions que ens interessa dur a terme, redactarem un informe on s'expliqui l'avaluació realitzada. També s'hi adjuntaran les millores i canvis que es proposen fer, i els beneficis que aportaran.

Aquest informe presentat a la comunitat educativa del centre es pot compartir a la web de la Motxilla Bioclimàtica.

\section{Conclusions}

La Motxilla Bioclimàtica ha completat aquest curs la seva etapa de prova. S'ha assajat en alguns centres de secundària de les comarques de Lleida amb una bona resposta per part de professors i alumnes. Com a proposta didàctica ha demostrat que permet treballar nombrosos conceptes del currículum de secundària aplicant eines i procediments científics.

La Motxilla Bioclimàtica participa en l'objectiu global d'educar en ciències, medi ambient i salut partint d'un context quotidià i oferint-se com una eina més al servei de la comunitat educativa. 


\section{Referències}

Bakó-Biró, Z., Kochhar N., Clements-Croome D., Awbi, H. i Williams M. (2007). Ventilation Rates in Schools and Learning Performance. Proceedings of Clima 2007 WellBeing Indoors. Helsinki.
Pujol, R.M. (2003). La didáctica de las ciencies en la educación primaria. Ed. Síntesis. Madrid. Pp. 349.

Zeyer A., Dillon J. (2012). Science, Environment, Health. Towards a reconceptualization of three critical and inter-linked areas of education, International Journal of Science Education, 34, 2, 327-328. 